m36.p14

\section{Valence and spin states of iron in $(\mathrm{Mg}, \mathrm{Fe}) \mathrm{SiO}_{3}$ perovskite and post-perovskite at pressures of the Earth's lower mantle}

\section{Artem R. Oganov, Feiwu Zhang}

Laboratory of Crystallography, Department of Materials, ETH Zurich, Wolfgang-Pauli-Str. 10, CH-8093 Zurich, Switzerland.

Earth's lower mantle is believed to contain $\sim 75$ vol. $\%$ $(\mathrm{Mg}, \mathrm{Fe}) \mathrm{SiO}_{3}$ perovskite, 20 vol.\% (Mg,Fe)O ferropericlase, 5 vol. $\% \mathrm{CaSiO}_{3}$ perovskite. In the lowermost $\sim 200 \mathrm{~km}$ of the mantle, $(\mathrm{Mg}, \mathrm{Fe}) \mathrm{SiO}_{3}$ adopts the post-perovskite structure [1,2]. While the properties and behaviour of pure $\mathrm{MgSiO}_{3}$ phases are well understood (see e.g. ref. [2-5]), the effects of impurities most importantly iron and aluminium, are poorly known and the existing experimental studies are contradictory.

Here, we perform ab initio simulations that address the valence and spin states of iron impurities in $\mathrm{MgSiO}_{3}$ polymorphs. In agreement with [6] we find a valence disproportionation reaction: $3 \mathrm{Fe}^{2+} \rightarrow 2 \mathrm{Fe}^{3+}+\mathrm{Fe}^{0}{ }_{\text {metal }}$. This highly exothermic (and somewhat counterintuitive) reaction results in the predominance of $\mathrm{Fe}^{3+}$ impurities in lower mantle silicates and produces free metallic iron. It occurs both in perovskite and post-perovskite, Al-free and Al-rich, at all lower mantle pressures. In presence of $\mathrm{Al}^{3+}$, iron forms $\mathrm{Fe}^{3+}-\mathrm{Al}^{3+}$ coupled substitutions in perovskite, but separate $\mathrm{Fe}^{3+}-\mathrm{Fe}^{3+}$ and $\mathrm{Al}^{3+}-\mathrm{Al}^{3+}$ substitutions in post-perovskite. Only the high-spin state is found for $\mathrm{Fe}^{2+}$ impurities at all mantle pressures, while $\mathrm{Fe}^{3+}$ impurities on the Si-site are low-spin at all pressures in both phases. $\mathrm{Fe}^{3+}$ impurities on the $\mathrm{Mg}$-site are in the high-spin state in post-perovskite at all mantle pressures, but in perovskite we predict a high-spin - low-spin transition. The pressure at which this transition occurs strongly depends on the $\mathrm{Al}^{3+}$ content and according to our calculations increases from $76 \mathrm{GPa}$ for $\mathrm{Al}$-free to $134 \mathrm{GPa}$ for Al-bearing perovskites. This explains previous experimental results [e.g., 7,8], which were thought to contradict each other. These findings have important geophysical implications [9].

[1] Murakami M., Hirose K., Kawamura K., Sata N., Ohishi Y. (2004). Post-perovskite phase transition in $\mathrm{MgSiO}_{3}$. Science 304, 855-858.

[2] Oganov A.R. \& Ono S. (2004). Theoretical and experimental evidence for a post-perovskite phase of $\mathrm{MgSiO}_{3}$ in Earth's D" layer. Nature 430, 445-448.

[3] Oganov A.R., Brodholt J.P., Price G.D. (2001). The elastic constants of $\mathrm{MgSiO}_{3}$ perovskite at pressures and temperatures of the Earth's mantle. Nature 411, 934-937.

[4] Cordier P., Ungar T., Zsoldos L., Tichy G. (2004). Dislocation creep in $\mathrm{MgSiO}_{3}$ perovskite at conditions of the Earth's uppermost lower mantle. Nature 428, 837-840.

[5] Oganov A.R., Martoňák R., Laio A., Raiteri P., Parrinello M. (2005). Anisotropy of Earth's D" layer and stacking faults in the $\mathrm{MgSiO}_{3}$ post-perovskite phase. Nature 438, 1142-1144.

[6] Frost D.J., Liebske C., Langenhorst F., McCammon C.A., Tronnes R.G., Rubie D.C. (2004). Experimental evidence for the existence of iron-rich metal in the Earth's lower mantle. Nature 428, 409-412.

[7] Badro J., Rueff J.P., Vanko G., Monaco G., Fiquet G., Guyot F. (2004): Electronic transitions in perovskite: Possible nonconvecting layers in the lower mantle. Science 305, 383-386.

[8] Li J., Struzhkin V.V., Mao H.K., Shu J.F., Hemley R.J., Fei Y., Mysen B., Dera P., Prakapenka V., Shen G.Y. (2004). Electronic spin state of iron in lower mantle perovskite. Proc. Natl. Acad. Sci. 101, 1402714030 .

[9] Zhang F., Oganov A.R. (2006). Valence states and spin transitions of iron in the Earth's mantle silicates. Science, under review. m36.p15

\section{Investigation of Mn site configuration in wurtzite and rock-salt $\mathrm{Zn}_{1-\mathrm{x}} \mathrm{Mn}_{\mathrm{x}} \mathrm{O}$ by means of XAS experiments under pressure}

\author{
$\underline{\text { A. Polian }}^{\#}$, J. Pellicer-Porres*, J.A. Sans*, \\ J.F. Sanchez-Royo*, A. Segura*, J.P. Itié ${ }^{\star}$, A.M. Flank ${ }^{\&}$, \\ P. Lagarde L $^{\text {L }}$
}

\#Physique des Milieux Denses, IMPMC, CNRS-UMR 7590, Université P. et M. Curie, 140 Rue de Lourmel, 75015 Paris (France) * ICMUV, Universidad de Valencia, Burjassot, Valencia (Spain) \& Synchrotron SOLEIL, L'Orme des Merisiers, Saint-Aubin - 91192 GIF-sur-YVETTE CEDEX (France)

\section{Keywords: high-pressure phase transitions, X-ray absorption spectroscopy, semiconductor crystals}

The diluted magnetic semiconductor (DMS) alloy $\mathrm{Zn}_{1-\mathrm{x}} \mathrm{Mn}_{\mathrm{x}} \mathrm{O}$ and other wide gap DMS are the object of increasing interest since Dietl et al. [1] predicted ferromagnetic behavior at room temperature in these materials.

Thin films of this material, deposited on sapphire have been reported to keep the wurtzite structure for Mn atomic proportions up to $30 \%$ [2] or $35 \%$ [3]. There have been a few reports on ferromagnetic behavior at low temperature (45 K) [4] and at room temperature $[5,6]$ but the subject remains controversial as some authors report spin-glass [7] or paramagnetic behavior [3].

Some authors attribute the ferromagnetic behavior to the presence of Mn nanoclusters while EXAFS measurements indicate that $\mathrm{Mn}$ atoms are in substitutional configuration on $\mathrm{Zn}$ sites [4, 8], but they do not report a full XANES analysis that would be far more sensitive to the site configuration

In this context, EXAFS and XANES experiments under pressure are relevant as they would give very valuable information about the site configuration of $\mathrm{Mn}$ atoms in $\mathrm{Zn}_{1-\mathrm{x}} \mathrm{Mn}_{\mathrm{x}} \mathrm{O}$ at different pressures and in different crystalline phases (wurtzite and rock-salt) which, combined with other techniques, can provide a deep insight on the origin of ferromagnetism in this DMS alloy.

The main results obtaines in this study are:

- A phase transition to rocksalt occurs above $7 \mathrm{GPa}$ for both compositions.

- The transition corresponds to a tetrahedral ( octahedral configuration.

- A modification of the pre-edge feature and of the XANES is observed.

- The Mn-O distance is similar in the low pressure phase for both compositions but differs slightly in the high pressure phase. In any case they are larger than the $\mathrm{Zn}-\mathrm{O}$ distances in pure $\mathrm{ZnO}$.

- The second neighbor distance $(\mathrm{Mn}-\mathrm{Zn})$ for $\mathrm{Zn}_{0.95} \mathrm{Mn}_{0.05} \mathrm{O}$ is smaller than the equivalent distance $\mathrm{Zn}-\mathrm{Zn}$ in pure $\mathrm{ZnO}$, while the third one is identical.

- The local compressibilities for both compositions are the same than the compressibility for $\mathrm{ZnO}$

- The transition is reversible for $5 \% \mathrm{Mn}$ in $\mathrm{ZnO}$, but irreversible for $25 \% \mathrm{Mn}$ in $\mathrm{ZnO}$

[1] T.Dietl, et al., Science 287, 1019 (2000).

[2] S.W. Jung, et al., Appl. Phys. Lett 80, 4561 (2002).

[3] A. Tiwari, et al. Solid State Commun. 121, 371 (2002).

[4] Z.W. Jin, et al., Appl. Phys. Lett 83, 39 (2003).

[5] P. Sharma, et al., Nature Materials 2, 673 (2003).

[6] P. Sharma, et al., J. of Magnetism and Magnetic Materials 282, 115 (2004).

[7] T. Fukamura, et al., Appl. Phys. Lett 78, 958 (2001).

[8] H. Ofuchi, et al., Physica Scripta, T115, 614 (2005). 